\title{
TOXIC-METABOLIC DISORDERS
}

\section{E. COLI HEMOLYTIC-UREMIC SYNDROME}

A retrospective analysis of 37 children with Escherichia coli 0157:H7associated hemolytic-uremic syndrome (HUS) traced to contaminated hamburger meat is reported from the University of Washington, Children's Hospital, Seattle. The majority (95\%) had severe hemorrhagic colitis, 19 (51\%) had multisystem disease, and $6(16 \%)$ had neurological complications. Seizures occurred in 3, stroke in 3 , and 3 became comatose. Three ( $8 \%$ ) died, 1 en route to the hospital after a seizure and cardiorespiratory arrest. A poor outcome was seen in all 3 with coma, 2 of 3 with seizures, and 1 of 3 with focal neurologic abnormalities. (Brandt JR et al. Escherichia coli O157:H7-associated hemolyticuremic syndrome after ingestion of contaminated hamburgers. I Pediatr Oct 1994;125:519-526). (Reprints: Ellis D Avner MD, Department of Nephrology, CH-46, Children's Hospital and Medical Center, 4800 Sandpoint Way NE, PO Box 5371, Seattle, WA 98105).

COMMENT. Neurologic complications of the HUS occur in $14 \%$ to $83 \%$ of previously published outbreaks. They were the most common cause of death in one report. The outbreak of E coli HUS in Seattle was a tragic reflection of the hazards of "Environmental Poisons in Our Food" (Millichap JG, PNB Publ, 1993). The importance of this topic in neurologic practice is emphasized by the inclusion of neurotoxicology symposia at the recent meeting of the Child Neurology Society and at the May 1995 annual meting of the American Academy of Neurology in Seattle.

\section{METHYLPHENIDATE ABUSE}

The clinical findings associated with IV methylphenidate/pentazocine abuse in emergency department visits are reported from the University of Missouri-Kansas City, MO. Twenty nine patients seen between 1987 and 1992 were treated 34 times. The mean age was $32+/-9$ years. Central nervous system complications in 7 were anxiety/agitation (5\%), seizures (9\%), or loss of consciousness (6\%). The typical symptom complex of chest pain, anxiety, muscle spasm, dizziness, and nausea was present in $58 \%$. Treatment was mainly supportive and included oxygen and fluids. (Carter HS, Watson WA. IV pentazocine/methylphenidate abuse - the clinical toxicity of another Ts and Blues combination. Clinical Toxicology 1994;32:541-547). (Reprints: Dr William A Watson, Department of Emergency Medicine, Truman Medical Center, 2301 Holmes, Kansas City, MO 64108).

COMMENT. IV abuse of methylphenidate is unlikely in children with ADDH but the increased use of stimulant medication in teenagers (see Ped Neur Briefs October 1994) provides a possible source of concern. The combination of crushed Talwin ${ }^{\circledR}$ (pentazocine) tablets and Ritalin ${ }^{\circledR}$ (methylphenidate) is called "Ts and Blues" in Kansas City, MO, and has resulted in acute myelopathy in one reported case. The CNS complications are reviewed by Caplan LR et al. (Neurology; 1982;32:623). 